\title{
Development of Sustainable Alkali-Activated Mortars Using Fe-Rich Fayalitic Slag as the Sole Solid Precursor
}

\author{
Adeolu Adediran, Juho Yliniemi* and Mirja Illikainen \\ Fibre and Particle Engineering Research Unit, University of Oulu, Oulu, Finland
}

Vast amounts of water-cooled non-ferrous metallurgy slags are generated yearly, and significant amounts are unutilized or dumped in landfills. To address this issue, in this study, $\mathrm{MgO}-\mathrm{FeOx}-\mathrm{SiO}_{2}$ fayalitic slag (FS) was used as the sole solid precursor (as an aggregate and binder) in alkali-activated mortars. The performance of the mortar samples was analyzed in terms of workability, density, compressive strength, and ultrasonic pulse velocity. The microstructural properties and binder composition of the samples were studied using a scanning electron microscope (SEM) coupled with energy

OPEN ACCESS

Edited by:

Rupert Jacob Myers, Imperial College London,

United Kingdom

Reviewed by:

Arne Peys,

Flemish Institute for Technological

Research (VITO), Belgium

Rodrigue Cyriaque Kaze,

University of Yaounde I, Cameroon

${ }^{*}$ Correspondence:

Juho Yliniem

juho.yliniemi@oulu.fi

Specialty section:

This article was submitted to

Sustainable Design and Construction,

a section of the journal

Frontiers in Built Environment

Received: 14 January 2021

Accepted: 08 March 2021

Published: 26 March 2021

Citation:

Adediran A, Yliniemi $J$ and

Illikainen M (2021) Development

of Sustainable Alkali-Activated

Mortars Using Fe-Rich Fayalitic Slag

as the Sole Solid Precursor.

Front. Built Environ. 7:653466.

doi: 10.3389/fbuil.2021.653466 dispersive X-ray spectroscopy (EDS). Experimental results revealed that mortar samples made with FS aggregates performed better, achieving a 28-day compressive strength of $21 \mathrm{MPa}$ compared to mortars produced with standard sand aggregates, which gained compressive strengths of $9 \mathrm{MPa}$. Further optimization of the particle size distribution of FS aggregate-based mortar samples using particle packing technology improved the workability, densified the mortar and yielded a mechanical performance of up to $40 \mathrm{MPa}$. FS aggregates have better interfacial bonding with the binder gel compared to standard sand, and the FS aggregates participate in the hardening reactions, consequently affecting the final binder phase composition, which consists of a $\mathrm{Na}_{2} \mathrm{O}-\mathrm{Fe}_{2} \mathrm{O}_{3}-\mathrm{SiO}_{2}$ gel with lower quantities of $\mathrm{CaO}, \mathrm{MgO}$, and $\mathrm{Al}_{2} \mathrm{O}_{3}$. Therefore, the alkali-activated mortars produced based on the optimization of fully recycled industrial residues can provide a pathway for the sole utilization of metallurgical by-products, which can have a wide range of structural applications.

Keywords: Fe-rich fayalite slag, aggregate, binder, alkali activation, mortar, interface region, ultrasonic pulse velocity, alkali-activated materials

\section{HIGHLIGHTS}

- Fayalite slag upcycling as sole solid precursor in alkali-activated mortars was demonstrated.

- Fayalite slag aggregate-based mortars have superior mechanical and microstructural properties than standard sand aggregate-based mortars.

- The properties of fayalite slag aggregate-based mortars were enhanced by particle packing.

- The chemical composition of interface region and binder gel was influenced by the aggregate type.

- The study provides a new sustainable pathway for full recycling of fayalite slag for use in construction industry. 


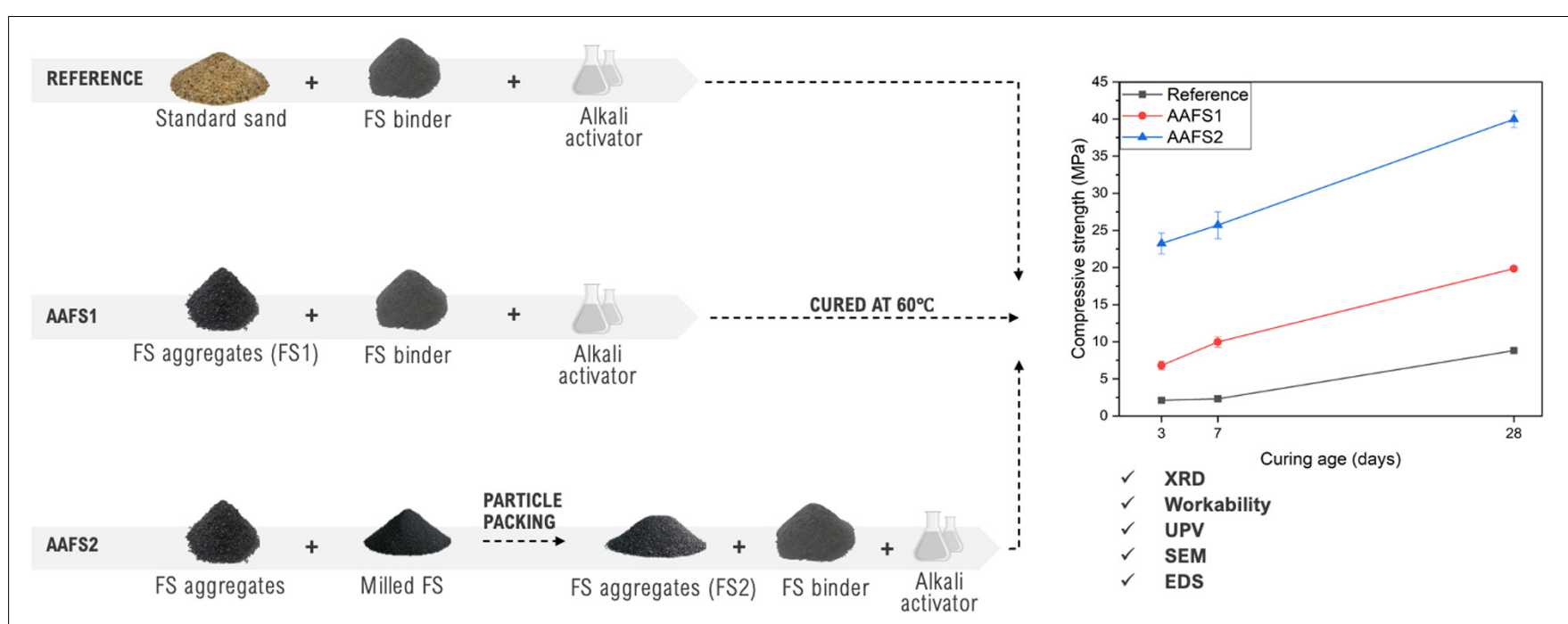

GRAPHICAL ABSTRACT | Development of sustainable alkali-activated mortars using Fe-rich fayalitic slag as the sole solid precursor.

\section{INTRODUCTION}

The increasing usage of Portland cement (PC) concrete in the construction industry and its consequences have been widely studied (Ali et al., 2011; Shi et al., 2011). Some of the critical issues identified include $\mathrm{CO}_{2}$ emissions during cement production, depletion of natural resources and the disruption of the natural ecosystem such as air, water, and soil contamination due to mining and the quarrying of aggregates (Mo et al., 2016).

To reduce the environmental impact from the cement and concrete industry, several alternatives have been proposed. Researchers have explored the possibility of replacing PC partially or wholly with various cementitious industrial residues (Alex et al., 2016; Provis, 2018). One notable breakthrough is the development of alternative alkali-activated binders from industrial residues, such as ground granulated blast furnace slag (GGBFS), coal fly ash, and more recently, mineral wools (Mo et al., 2015; Zhao et al., 2015; Provis, 2018; Carvelli et al., 2020; Lemougna et al., 2020). While GGBFS and coal fly ash have been widely researched and successfully applied in alkali-activated cements and concrete, they are already utilized almost fully as supplementary cementitious material (SCM) (Scrivener et al., 2016). Thus, other potential industrial residues should be investigated as precursors for alkali-activated materials (AAMs). One recently studied residue is fayalite slag (FS) (Onisei et al., 2015, 2018).

Fayalite slag is an Fe-rich industrial residue and a nonferrous metallurgy slag generated from nickel and copper production, and significant amounts of this slag remain unutilized (Marangoni et al., 2016). This slag is named FS due to its main mineralogical crystalline component. The chemical properties of the slag are influenced by its cooling process and cooling rate. Slowly cooled FS results in a hard, crystalline product, while the water cooling of FS enhances quick solidification, resulting in an amorphous/glassy slag (Fan et al., 2014; Siakati et al., 2020). Water-cooled FS comes in a granular form with particle sizes ranging from 0 to $4 \mathrm{~mm}$, and its production has continued to rise yearly with the increasing demand for nickel and copper (Michailova and Mehandjiev, 2010). For example, in Finland, approximately 200,000 tons of water-cooled FS are produced every year, most of which is currently landfilled but can potentially be utilized as AAM precursors (Saari et al., 2019).

In the last few years, several Fe-rich materials have been investigated for their suitability as precursors for AAMs. Such materials include bauxite residue slags, low calcium slags from ferronickel production, lead and zinc slags, laterite soils and Fesilicate glasses from various mining residues (Komnitsas et al., 2007; Hertel et al., 2016; Machiels et al., 2017; Millán-Corrales et al., 2020; Kaze et al., 2021a; Rodrigue Kaze et al., 2021). Similar to other Fe-rich materials, FS is suitable for use as a precursor for AAMs (Komnitsas et al., 2020). The presence of amorphous material in FS is beneficial for its reactivity in terms of alkali activation (Onisei et al., 2015, 2018). The amorphous phase of FS is the phase with the most substantial reactivity, and it can be used as a binder precursor if milled into fine particle sizes $\left(\mathrm{d}_{50} \sim 10 \mu \mathrm{m}\right)$ and mixed with an alkali activator (mostly alkali hydroxide and/or alkali silicate) (Machiels et al., 2014; Onisei et al., 2015).

The reactivity of FS in alkaline solution is quite low compared to those of aluminosilicate precursors, reasonably due to their distinct chemical and mineralogical composition (Onisei et al., 2015). FS is rich in iron oxide and silica with lower amounts of calcium and alumina, which affects its reactivity and the binder formed. Alkali-activated FS binders have been reported to present a unique reaction pathway compared to other aluminosilicate precursors (Peys et al., 2019b,c). After the initial dissolution of FS, a complex reaction mechanism results in the formation of two products. The first reaction product is formed as a result of the precipitation of $\mathrm{Fe}^{2+} ; \mathrm{Fe}^{2+}$ ions are arranged in an octahedral configuration. The second reaction product is related to the silicate network; it contains an $\mathrm{Fe}^{3+}$ charge located in the 
tetrahedral bonding network of the binder gel, with Na playing a charge balancing role (Peys et al., 2019b,c). Thus, iron plays an important role in the binder gel and displays a different nanostructural chemistry from conventional AAMs.

Different studies have reported the use of Fe-rich precursors in alkali-activated mortars. Researchers have shown that alkaliactivated mortars can be obtained from a mixture of a milled precursor and standard sand (i.e., a milled Fe-rich precursor is used as the binder while sand is used as an aggregate) (Komnitsas et al., 2007, 2019; Kalinkin et al., 2012; Machiels et al., 2014; Albitar et al., 2015; Nazer et al., 2016; Iacobescu et al., 2017; Xia et al., 2019). However, the water-cooled FS used in this study can also be utilized without the need for milling as it has a suitable particle size for sand replacement in mortars. Preliminary tests on the use of FS as an aggregate and binder in AAMs showed that the mortar samples with FS aggregates had superior mechanical properties compared to mortar samples with standard sand aggregates (Adediran et al., 2019). However, considering the beneficial use of this industrial residue for dual purposes (i.e., as a natural aggregate and for cement replacement), further investigations are necessary to obtain a comprehensive understanding of the behavior of FS as an aggregate and its influence on the chemical composition of the binder phase formed.

This study provides detailed information on the use of FS as a sole solid precursor (aggregate and binder) in AAMs. The study focuses on the optimization of the mortars based solely on FS to achieve optimal performance and to provide detailed information on the binder gel composition and the microstructure near the aggregates. Three mix compositions with similar binder types and amounts of alkali activators were developed. The reference mix contained standard sand aggregates, and the second mix contained FS aggregates. However, the third mix was formulated using particle packing, and the influence on the properties of alkali-activated slag mortars was investigated. The physical and chemical properties of the prepared mortars were assessed, and the mineralogy was determined using X-ray diffraction (XRD). The workability of the fresh mortar samples was determined using a flow table test. Scanning electron microscope (SEM) and energy dispersive X-ray spectroscopy (EDS) was used to determine the microstructure and elemental composition of the binder phase formed. The ultrasonic pulse velocity (UPV) and compressive strength of the mortar samples were measured at 3 , 7 , and 28 days of curing. The results of the FS aggregate-based samples obtained were compared with those of the reference mix. This study provides a good understanding of the microstructural evolution that takes place between FS aggregates and FS binders and provides a new pathway for recycling FS as a sole solid precursor in AAMs.

\section{MATERIALS AND METHODS}

\section{Experimental}

Industrial water-cooled FS, which originated from nickel production, was obtained from Boliden Harjavalta Oy (Finland). The chemical composition of FS as determined using X-ray fluorescence (PANalytical Omnian Axiosmax) from a melt-fused tablet and loss on ignition (LOI, measured with PrepAsh, Precisa) is shown in Table 1. The major oxides present in FS are $\mathrm{Fe}_{2} \mathrm{O}_{3}, \mathrm{SiO}_{2}$, and $\mathrm{MgO}$ along with other minor oxides, and it is similar to other slags obtained from copper production (Michailova and Mehandjiev, 2010; Adediran et al., 2021). In $\mathrm{FS}$, iron may exist as $\mathrm{Fe}^{+2}$ and $\mathrm{Fe}^{+3}$, but it is reported here as $\mathrm{Fe}_{2} \mathrm{O}_{3}$ due to the $\mathrm{X}$-ray fluorescence sample pre-treatment using thermogravimetric analysis at $950^{\circ} \mathrm{C}$ during which the iron oxidizes mostly into $\mathrm{Fe}^{+3}$, depicted by the negative LOI in Table 1.

X-ray diffraction patterns of FS were determined using a Rigaku Smartlab diffractometer, with a $\mathrm{Cu}$ K-beta radiation and a scanning rate of $0.02^{\circ} 2 \theta /$ step from $5-80^{\circ}$, operated at $135 \mathrm{~mA}$ and $40 \mathrm{kV}$. The quantification of the amorphous phases was done with 10 wt. $\%$ rutile $\left(\mathrm{TiO}_{2}\right)$ as the internal standard. The Rietveld refinement method was used for the qualitative and quantitative analysis of the crystalline phase (Rietveld, 1969).

$\mathrm{X}$-ray diffraction results in Table 2 revealed that FS consisted mainly of fayalite $\left[\left(\mathrm{Fe}_{2} \mathrm{SiO}_{4}\right)\right.$, pdf. 04-007-9022] and magnetite [( $\left.\mathrm{Fe}_{3} \mathrm{O}_{4}\right)$, pdf. 04-008-8145] as the crystalline components while the rutile [ $\left(\mathrm{TiO}_{2}\right)$, pdf. 04-008-7847] peak present in Figure 1 is as a result of the internal standard used. The amorphous fraction (55.5 wt.\%) in FS is higher than that of the crystalline phase, and the amorphous phase is the only phase with significant reactivity (Iacobescu et al., 2017; Onisei et al., 2018).

Standard sand conforming to European standard EN 196-1 (EN 196-1, 2016) with a particle size distribution (PSD) between 0.08 and $2 \mathrm{~mm}$ and a maximum moisture content of $0.2 \%$, was used as the reference aggregate. The FS was moist when received and then dried in the oven at a temperature of $60^{\circ} \mathrm{C}$ overnight to remove the moisture. The slag was then sieved using a $2 \mathrm{~mm}$ mesh to remove particles $>2 \mathrm{~mm}$, and the PSD was determined using the sieving method (EN 933-1, 2000). The sieve analysis results revealed that the PSD of FS was different from that of standard sand. Thus, the PSD of FS was modified to achieve a PSD similar to that of standard sand (named "FS1"). To achieve optimized particle packing, the FS was ball-milled for $30 \mathrm{~min}$ to achieve a median particle size $\left(\mathrm{d}_{50}\right)$ of $248 \mu \mathrm{m}$; this was optimized with FS by particle packing technology using the Elkem Material Mixture Analyzer (EMMA) based on a modified Andreasen's particle packing model. A distribution coefficient (q) of 0.29 was used, and the particle size was fixed between 0.1 and $2000 \mu \mathrm{m}$. The optimization curve for the aggregate fraction can

TABLE 1 | Chemical composition of FS as weight-\%.

\begin{tabular}{ccccccc}
\hline $\mathrm{Fe}_{\mathbf{2}} \mathbf{O}_{\mathbf{3}}$ & $\mathrm{SiO}_{\mathbf{2}}$ & $\mathrm{MgO}$ & $\mathbf{A l}_{\mathbf{2}} \mathbf{O}_{\mathbf{3}}$ & $\mathbf{C a O}$ & Others & LOI at $\mathbf{9 5 0}^{\circ} \mathbf{C}$ \\
\hline 52.5 & 34.4 & 6.8 & 2.4 & 1.9 & 1.8 & -0.2 \\
\hline
\end{tabular}

TABLE 2 | Mineralogical composition of FS as weight-\%.

\begin{tabular}{ccc}
\hline Fayalite & Magnetite & Amorphous \\
\hline 42.4 & 2.1 & 55.5
\end{tabular}




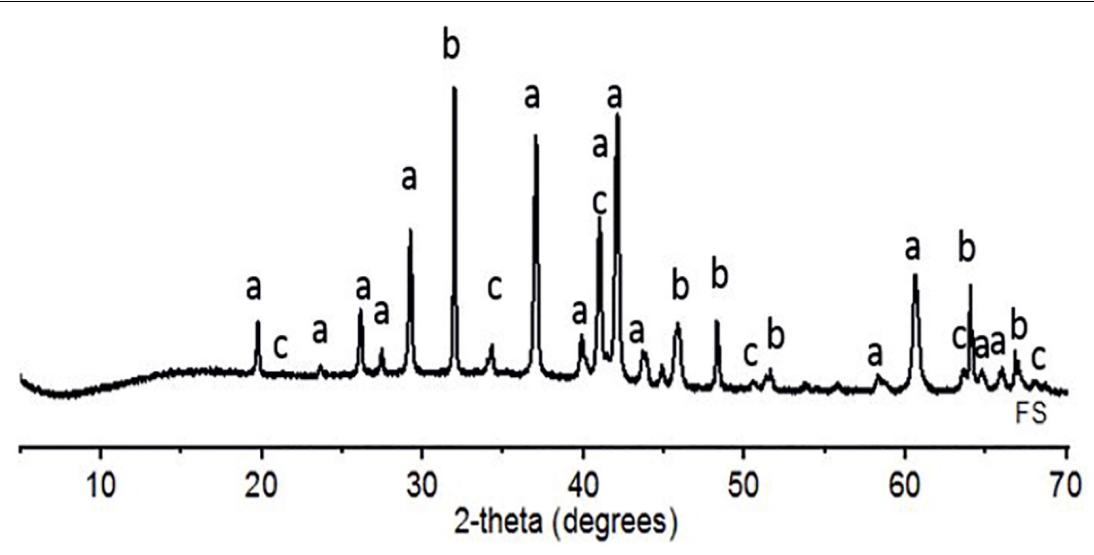

FIGURE 1 |XRD pattern (2-theta $10-70^{\circ}$ ) of raw FS with the main phases (a, fayalite; b, rutile $\left(\mathrm{TiO}_{2}\right)$; and c, magnetite).

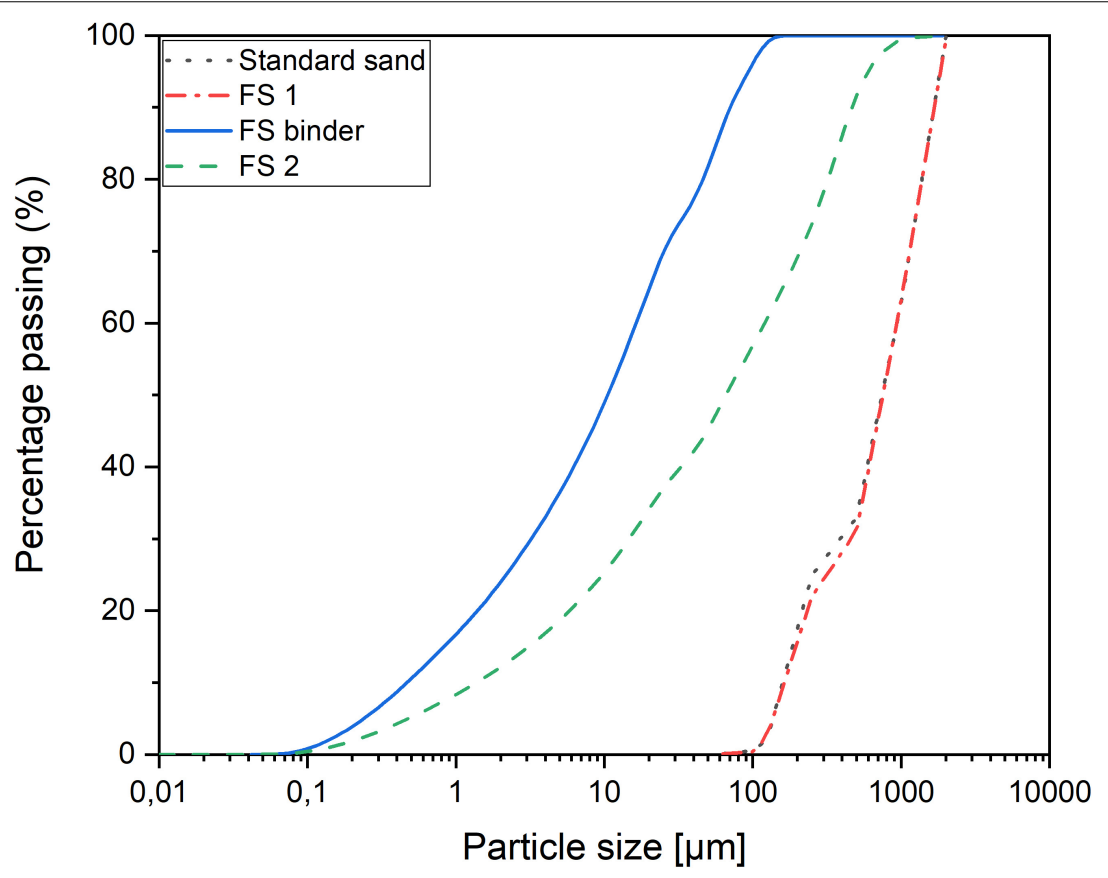

FIGURE 2 | Particle size distribution of FS 1, FS 2, standard sand and FS binder.

be found in the Supplementary Material. This aggregate fraction is named "FS2".

Fayalite slag to be used as a binder precursor (named "FS binder") was ball-milled for three hours in a laboratory tumbling ball mill (Germatec, Germany) to achieve a $\mathrm{d}_{50}$ of $10 \mu \mathrm{m}$. The PSD was analyzed using a Beckman Coulter LS 13320 laser diffraction particle size analyzer. Water was used as a dispersion medium during measurement. The PSD of the aggregates and the binder are presented in Figure 2.

Fayalite slag has a higher specific gravity than that of standard sand (3796 vs. $2674 \mathrm{~kg} / \mathrm{m}^{3}$ ) due to its high iron content. In addition, the bulk density of FS $\left(2192 \mathrm{~kg} / \mathrm{m}^{3}\right)$ is higher than that of standard sand $\left(1544 \mathrm{~kg} / \mathrm{m}^{3}\right)$, indicating that the use of FS as an aggregate may produce an alkali-activated mortar of higher density. The fineness modulus of FS is similar to that of standard sand, which can be obtained from the PSD (Figure 2). The water absorption of FS is $0.4 \%$ compared with $0.2 \%$ for standard sand. The shape of the particle as viewed using the optical microscope indicated that FS particles are angular in shape with no roundness, but those of standard sand are mostly rounded in shape and less angular (Figure 3).

\section{Sample Preparation}

The alkali-activated mortars were prepared according to the following procedure. The alkaline solution utilized for the synthesis was a mix of a $10 \mathrm{M}$ sodium hydroxide solution and an analytical grade sodium silicate solution (Merck, United States). The sodium silicate solution used was composed of $65.5 \% \mathrm{H}_{2} \mathrm{O}$ $\left(\mathrm{Na}_{2} \mathrm{O}: 7.5-8.5 \%, \mathrm{SiO}_{2}\right.$ : 25.5-28.5\%, density: $\left.1.296-1.396 \mathrm{~g} / \mathrm{ml}\right)$. A sodium hydroxide solution was prepared using analytical 

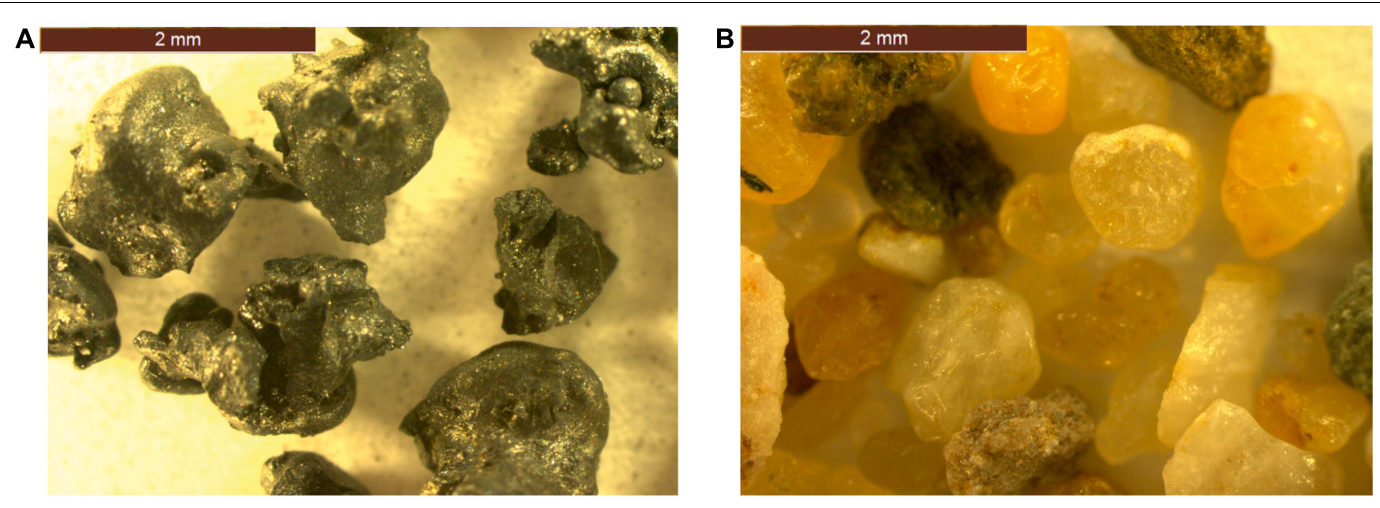

FIGURE 3 | Optical micrograph of aggregates. (A) FS aggregates; (B) standard sand aggregates.

grade sodium hydroxide pellets ( $>98 \%$ purity; VWR Chemicals) dissolved in deionized water. The choice of a $10 \mathrm{M}$ sodium hydroxide solution for the synthesis was based on the results of the preliminary experiment and on previous studies on the alkali activation of FS (Adediran, 2017; Adediran et al., 2019). The mass ratio of sodium silicate to sodium hydroxide was 50:50. The final molar ratios of the activating solution were $\left(\mathrm{SiO}_{2} / \mathrm{Na}_{2} \mathrm{O}=1.0\right)$ and $\left(\mathrm{H}_{2} \mathrm{O} / \mathrm{Na}_{2} \mathrm{O}=15.7\right)$. The solution was prepared $24 \mathrm{~h}$ before mixing.

Three mix designs were developed based on the knowledge of the properties of all ingredients and presented in Table 3. The water to binder ratio for all the mortars was held constant at 0.30 . The reference mix consisted of FS binder and standard sand aggregates. However, systematic modification was performed on the mix design of the samples that had FS aggregates. The mass fraction of aggregates used in AAFS1 and AAFS2 were more than that of standard sand used in the reference mix due to the higher density of FS. Meanwhile, the volume fraction of the aggregates for all the mixes remained the same and was kept constant at 3 . The type and amount of the binder component used was also held constant for all the mixes regardless of the aggregate type to ensure a similar amount for sample preparation.

The mixing of all the mortar samples was done mechanically in accordance with the EN 196-1 standard (SFS-EN 196-1, 2011). The workability of fresh mortar mixtures was evaluated using a flow table test in accordance with the EN 1015-3 standard (SFS-EN 1015-3, 1999). The mixture was then cast into a $20 \times 20 \times 80 \mathrm{~mm}^{3}$ oiled rectangular prism mold for strength measurement and a $40 \times 40 \times 160 \mathrm{~mm}^{3}$ mold for UPV measurement, and a jolting machine (60 shocks, $1 / \mathrm{s}$ ) was used for compacting. All the samples were sealed in a plastic bag and cured at $60^{\circ} \mathrm{C}$ for $24 \mathrm{~h}$. The samples were removed from the oven after $24 \mathrm{~h}$ and demolded. Then, the samples were kept at room temperature (approximately $23^{\circ} \mathrm{C}$ ) and sealed in a plastic bag until testing after 3,7 , and 28 days of curing.

\section{Test Procedures}

The unconfined compressive strength (UCS) was determined using a Zwick testing machine (Zwick Roell Group, Ulm,
Germany) with a maximum load of $100 \mathrm{kN}$ and a loading force of $2.4 \mathrm{kN} / \mathrm{s}$. For each mix proportion, at least four replicate specimens were tested, and the average was regarded as the representative value of the strength measurement. The error bar in the strength measurement graph indicates the double standard deviation between the specimens.

Ultrasonic pulse velocity measurement was carried out using the Matest C369N to determine the quality of the mortars and microstructural development over time. Two $55 \mathrm{kHz}$ transducers ( $\pm 2 \%$ accuracy for distance and $\pm 1 \%$ accuracy for travel time) were connected to the UPV testing machine to determine the velocity of an ultrasonic wave passing through the mortars. Prior to placing the transducers on the surface of the samples, Vaseline was used to lubricate the transducers and ensure proper contact with the sample surface. A lower UPV value indicates the presence of voids and cracks while a higher UPV value suggests the formation of a denser microstructure. The UPV test was carried out in accordance with American Society for Testing and Materials (ASTM) C597 recommendations using Eq. 1:

$$
V=y / t
$$

where $V$ is the UPV value $(\mathrm{m} / \mathrm{s})$, which is a function of the distance, $y$, between two transducers $(m)$ and the transit time, $t(s)$.

For each mix proportion, at least four replicate specimens were tested, and the average was regarded as the representative value of the UPV measurement. The error bar in the UPV measurement graph indicates the double standard deviation between the specimens.

The density of hardened samples after 28 days of curing was determined according to ASTM C642 recommendations (ASTM C642, 2013). All the mortar samples were first dried in the oven at a temperature of $110^{\circ} \mathrm{C}$ for $24 \mathrm{~h}$. The samples were then removed from the oven and kept at room temperature to cool down before weighing.

\section{Microstructural Characterization}

The microstructure of the samples was studied using SEMEDS analysis. The reliability of the results obtained from SEM analysis depends on the quality of the surface of mortar samples 
to be tested. After 28 days of curing, the prepared mortar samples were cut into smaller pieces and casted in epoxy resin for polishing. The samples were then subjected to subsequent grinding and polishing steps using ethanol as a lubricant to prevent further hydration and dissolution. The samples were then coated with carbon and analyzed using SEM-EDS (Zeiss Ultra Plus, Germany). The microstructural characteristics of the mortar samples were analyzed and compared using a backscatter electron detector with an accelerating voltage of $15 \mathrm{kV}$.

\section{RESULTS AND DISCUSSION}

\section{Workability and Density of Alkali-Activated Mortars}

The workability of all the mortar samples prepared is presented in Table 4. AAFS2 had the maximum workability (169 mm). The workability of AAFS1 was $146 \mathrm{~mm}$ and that of the reference mix was $160 \mathrm{~mm}$. The high workability of AAFS2 can be attributed to the packing effect (Supplementary Material) as the higher content of fine particles in the matrix of AAFS2 was able to fill up the spaces between the larger particles, allowing lubrication of the mix. The difference in the workability values of AAFS1 and the reference mix could have been as a result of aggregate properties. The higher workability of the reference mix compared to AAFS1 may be due to the rounded particle shape of standard sand aggregates. Similar observations of high workability have also been reported when round-shaped natural river sand was used as an aggregate unlike the angular-shaped crushed limestone aggregate in fly ash geopolymer mortar (Mermerdaş et al., 2017).

The density of hardened AAFS2 mortars was higher compared to that of AAFS1 mortar samples due to the better packing of particles. Furthermore, the density of the mortar samples prepared with FS aggregates (AAFS2 and AAFS1) were higher than the reference mortars with standard sand aggregates (Table 4). This can be attributed to the high specific gravity of FS.

TABLE 3 | Mix proportion of mortar samples.

\begin{tabular}{|c|c|c|c|c|c|c|}
\hline \multirow[t]{2}{*}{ Sample name } & \multicolumn{3}{|c|}{ Aggregates (g) } & \multirow[t]{2}{*}{ FS binder (g) } & \multirow{2}{*}{$\begin{array}{l}10 \mathrm{M} \mathrm{NaOH} \\
+\mathrm{Na}-\mathrm{Sil}(\mathrm{g})\end{array}$} & \multirow[t]{2}{*}{$\mathbf{w} / \mathbf{b}^{* \star}$} \\
\hline & Sand & FS1 & FS2* & & & \\
\hline Reference & 804 & & - & 396 & 200 & 0.3 \\
\hline AAFS1 & - & 1139.9 & - & 396 & 200 & 0.3 \\
\hline AAFS2 & - & - & 1139.9 & 396 & 200 & 0.3 \\
\hline
\end{tabular}

${ }^{*}$ FS2 consists of $560.5 \mathrm{~g}$ of as-received FS and $579.4 \mathrm{~g}$ of milled FS with $d_{50}$ of $248 \mu \mathrm{m}$.

${ }^{* *} w / b$ is water to binder ratio.

TABLE 4 | Workability and density values of the alkali activated mortar samples.

\begin{tabular}{lcc}
\hline Sample name & Mean workability $\mathbf{( m m )}$ & Density $\mathbf{( k g / \mathbf { m } ^ { \mathbf { 3 } } )}$ \\
\hline Reference & $160 \pm 1.3$ & 2228 \\
AAFS1 & $146 \pm 1.2$ & 2688 \\
AAFS2 & $169 \pm 1.2$ & 2931
\end{tabular}

\section{Compressive Strength}

The compressive strength of AAFS2 was higher than those of AAFS1 and the reference mix as presented in Figure 4. The compressive strength of both AAFS2 and AAFS1 after 28 days of curing was relatively good (i.e., 40 and $21 \mathrm{MPa}$ ) and can be suitable for structural clay load-bearing wall tiles, pedestrian and light traffic paving bricks (ASTM C34-03, 2003), for example. The compressive strengths also satisfied the ASTM C62-99 recommendation of $20.7 \mathrm{MPa}$ for building bricks (ASTM C62, 1999).

The dense packing of aggregates and binders had a remarkable positive effect on the compressive strength of AAFS2 mortar samples. AAFS2 had the highest early age strength at 3 days followed by AAFS1, and a much lower early age strength was observed in the reference mix. The introduction of small-sized aggregates in the matrix formulation of AAFS2 via particle packing might have contributed to its mechanical behavior at early and late age when compared to AAFS1. The optimum packing of aggregates and the binder is believed to have reduced porosity and void in the mortar and increased the affinity between the mortar components, which is very important for the mechanical properties of the mortar. The strength achieved in AAFS2 is comparable to those obtained for alkali-activated composites made from calcined iron-rich laterite soil cured at elevated temperature (Kaze et al., 2021b).

The difference in compressive strength between the reference and AAFS1 samples could be ascribed to the angular shape of the FS aggregates and chemical bonding between FS aggregates and the FS binder (later shown in section "SEM-EDS"). Angular particles have been reported to have higher bonding characteristics, which create stronger interlinking of the particles as a result of the higher surface to volume ratio (Mermerdaş et al., 2017; Lyu et al., 2019). The observation in this study is consistent with the findings of other researchers on the use of other iron-rich slags, such as copper slag and ferronickel slags, as aggregate replacements in cement-based mortars and concrete paving blocks (Ayano and Sakata, 2000; Al-Jabri et al., 2011; Dimitrioglou et al., 2015; Mithun and Narasimhan, 2015). When copper slags were used as fine and coarse aggregates, the mechanical properties were similar or superior to those of the reference mixtures containing sand. Additionally, copper slags were found to have higher compressive strength as coarse aggregates in high strength concrete than limestone aggregates as a result of the stronger bonding between copper slag aggregates and the matrix (Khanzadi and Behnood, 2009). Thus, the lower strength exhibited by the reference mix may likely be due to the low chemical interaction between aggregates and the binder (see section "SEM-EDS") and the round shape and smooth surface of standard sand, which led to a lower bonding strength with the FS binder.

\section{Ultrasonic Pulse Velocity}

AAFS2 mortar samples had higher UPV values compared to AAFS1 and reference samples as shown in Figure 5. This indicates that there were less voids and defects in AAFS2, and the matrix was denser and more compact compared to AAFS1 and 


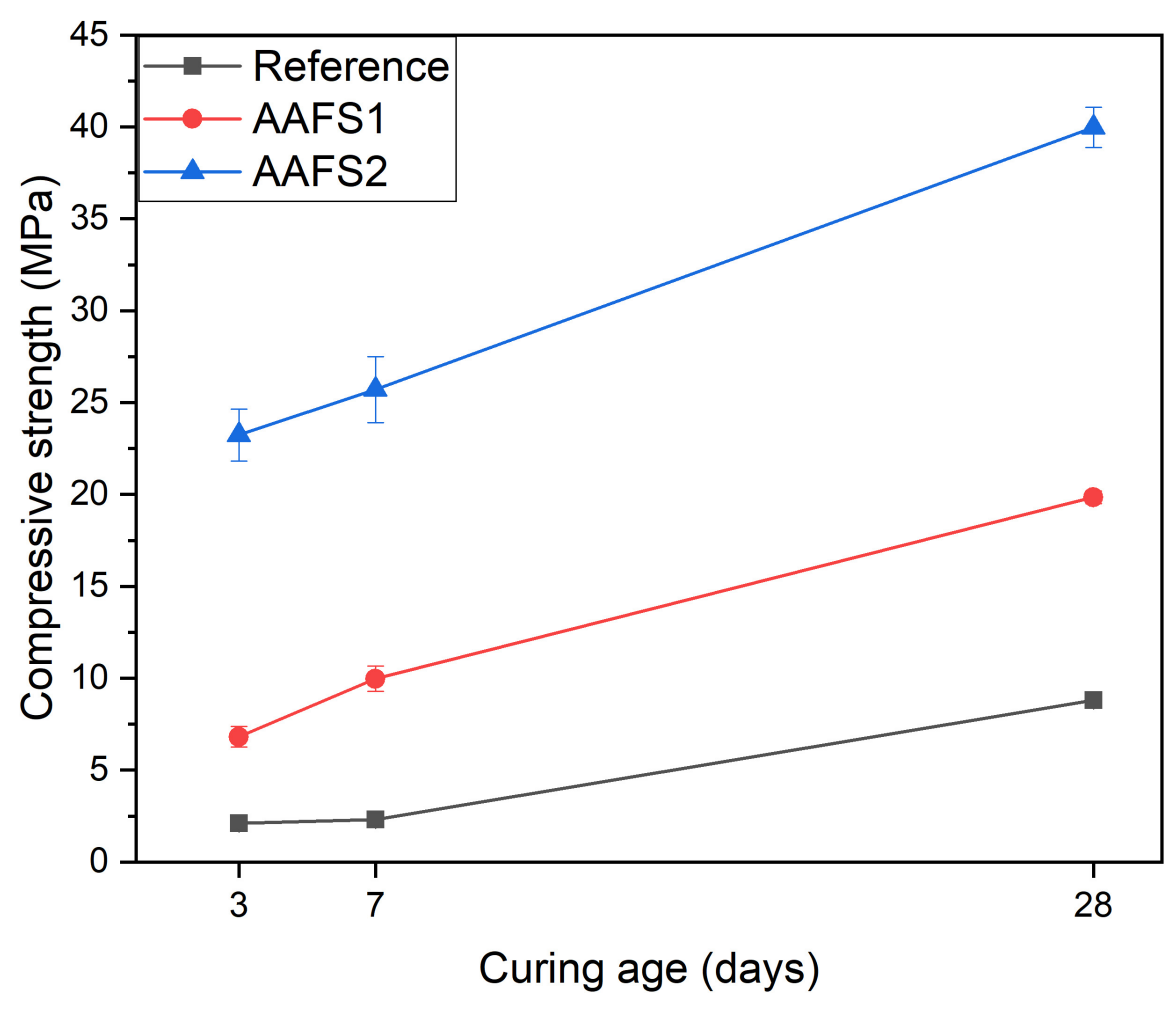

FIGURE 4 | Compressive strength of mortar samples at 3, 7, and 28 days of curing.

reference samples, assuming that all the samples have comparable stiffness. The reason for higher UPV values in AAFS2 can be attributed to densified particle packing of aggregates and the binder, which prevents the formation of internal voids in the mortar thereby increasing the mortar quality. Hence, the internal structure of mortars can be improved by particle packing. Furthermore, the aggregate type used can influence the mortar microstructure. Reference mortars prepared with round-shaped standard sand had lower UPV values than AAFS1 mortars with angular FS aggregates as a result of weaker bonding between the standard sand aggregate and the binder (Figure 7). This is in line with similar observations from other studies, which have reported that aggregate type can influence the prediction of UPV values of composite mixtures (Trtnik et al., 2009). The increase of UPV values for all the mortars correlates with the rate of strength development in Figure 4. A similar correlation between the UPV and compressive strength has been reported in fly ashbased geopolymer concrete and blast furnace slag-based concrete (Omer et al., 2015; Ghosh et al., 2018).

\section{SEM-EDS}

The SEM micrographs with $500 \times$ and $2000 \times$ magnifications of representative sections of mortar samples after 28 days of curing are presented in Figures 6, 7. The micrographs of the reference sample (Figure 6A) appear to show a weak interface between the standard sand aggregate and the binder gel formed, which becomes more visible at higher magnifications (Figure 7A). The standard sand aggregate appears intact with bond cracks at the interface, suggesting that the chemical bonding between sand particles and the binder gel is relatively low. The reason for this low interaction might be that standard sand consists of crystalline quartz, which is not dissolved by the activating solution and does not interact with the binder.

In comparison to the reference mix, AAFS1 mortar samples in Figure 6B showed a less distinct interface between the FS aggregates and the surrounding binder gel formed. Only the iron silicate glass phase dissolved to form the binder gel, and the crystalline phases were left over and tightly embedded in the binder matrix (Figure 7). This can be observed particularly in Figure 7C where the region circled with white rings shows excessive dissolution of the glass phase during alkali activation. Thus, FS aggregates seem to chemically bind and adhere more closely to the binder gel (Figure 7B), exhibiting a more compact and stronger interface. The micrograph of AAFS2 mortar samples in Figure 6C appears denser with less crack propagation at the interface when compared to that of AAFS1, indicating higher affinity and bonding between the aggregates and the binder gel formed and is consistent with the compressive strength and UPV results in sections "Compressive Strength" and "Ultrasonic Pulse Velocity." The reactivity of FS aggregates is further confirmed by the presence of more Fe ions in the interface region compared to reference mortars according to EDS (data not shown). Similar higher concentration of calcium was observed at the interface region when calcium-rich steelwork aggregate was used as aggregate in fly ash based mortar samples (Cristelo et al., 2019). 


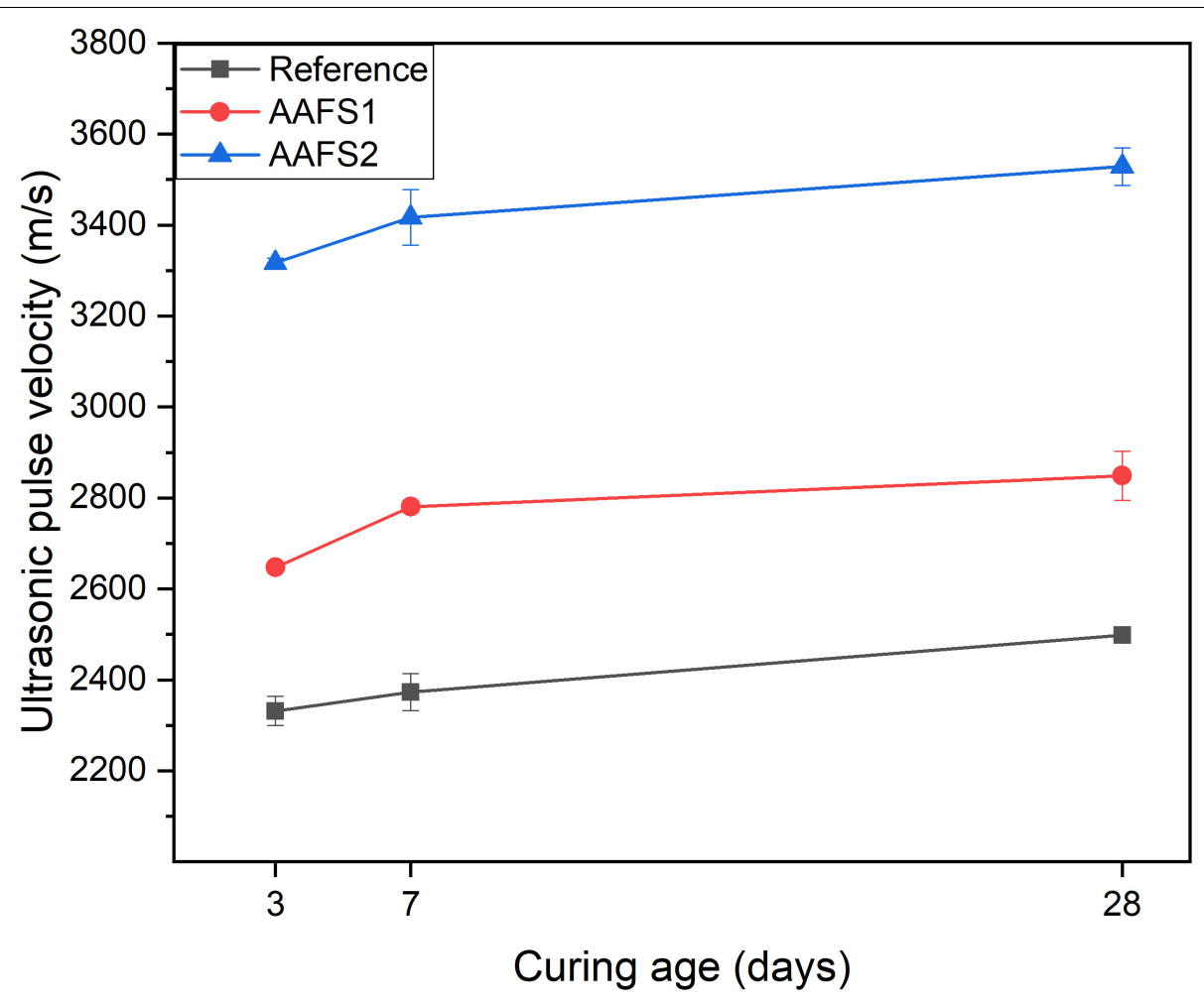

FIGURE 5 | Ultrasonic pulse velocities of mortar samples at 3, 7, and 28 days of curing.

In all the mortar samples, the partially dissolved and unreacted slag particles acted as small aggregates and fillers in the matrix (Figures $6 \mathrm{~A}-\mathrm{C}, 7 \mathrm{~A}-\mathrm{C}$ ). These unreacted slag particles, as revealed by the microstructure, are relics of fayalite crystals and magnetite, consistent with the crystalline phase observed in XRD analysis shown in Figure 1. Particularly in AAFS2, a high volume of binder gel formed cover the surface of FS particles at the interface region, ascribed to the beneficial effect of the addition of small-sized aggregates to the matrix. This implies that as AAFS2 contained more small-sized particles compared to AAFS1, the particles did not only act as a filler to improve particle packing, but also partly dissolved, thereby contributing additional Fe ions to the interface region.

Furthermore, there was a difference in the size of particles located in the interface region compared to that of bulk binder region in AAFS2 (Figure 7C). The size of the particles near the interface region appeared smaller, with the core of unreacted particles located in the bulk binder (Figure 7C). One possible explanation could be that due to better particle packing, the smaller particles were able to fill the voids between larger particles and were closely packed through the surface of the aggregates. Smaller-sized particles close to the interface had higher surface areas in comparison to larger particles further out, leading to a higher release of ions such as Fe into the interface region. As a result, a denser microstructure was formed in the interface region, and this is important for the long-term performance of the mortar.
Crack formation, known as "matrix crack," was noticeable in the binder gel of all the samples, and this became more pronounced at higher magnifications (Figures $7 \mathrm{~A}-\mathrm{C}$ ). The cracks formed penetrated through the binder gel and sometimes terminated at the aggregate boundary. The crack formed could likely be associated with specimen preparation, exposure to vacuum conditions during SEM analysis or curing of samples as the samples were cured at an elevated temperature of $60^{\circ} \mathrm{C}$. A similar network of cracks has also been reported when copper production-based FS was used as precursor for AAM and cured at $60^{\circ} \mathrm{C}$ (Iacobescu et al., 2017).

The EDS point analysis of binder gel formed for all the mortar samples are summarized in Figure 8. EDS analysis has some drawbacks as it is only semi-quantitative, and it is possible that data points represent a mixture of several binder phases or undissolved particles if they are mixed on a scale smaller than the depth of X-ray generation for the $15 \mathrm{kV}$ accelerating voltage used (i.e., $<5 \mu \mathrm{m}^{3}$ ). However, the average and standard deviation of several points located on the studied phase could give an insight into the composition of the phase. The elemental composition of the binder gel formed in all the mortar samples was compared with that of the glass phase of FS. The binder gel formed in all the samples after 28 days of curing consisted mainly of $\mathrm{Si}, \mathrm{Fe}$, and $\mathrm{Na}$, with lower quantities of $\mathrm{K}, \mathrm{Ca}, \mathrm{Al}$, and $\mathrm{Mg}$. This is in line with earlier study of alkali-activated Fe-silicate glasses (Machiels et al., 2014). However, in the mentioned study, the slag composition was slightly different as it had more $\mathrm{Ca}$ and less $\mathrm{Mg}$, which may explain why their binder had higher concentrations of $\mathrm{Ca}$ in the 

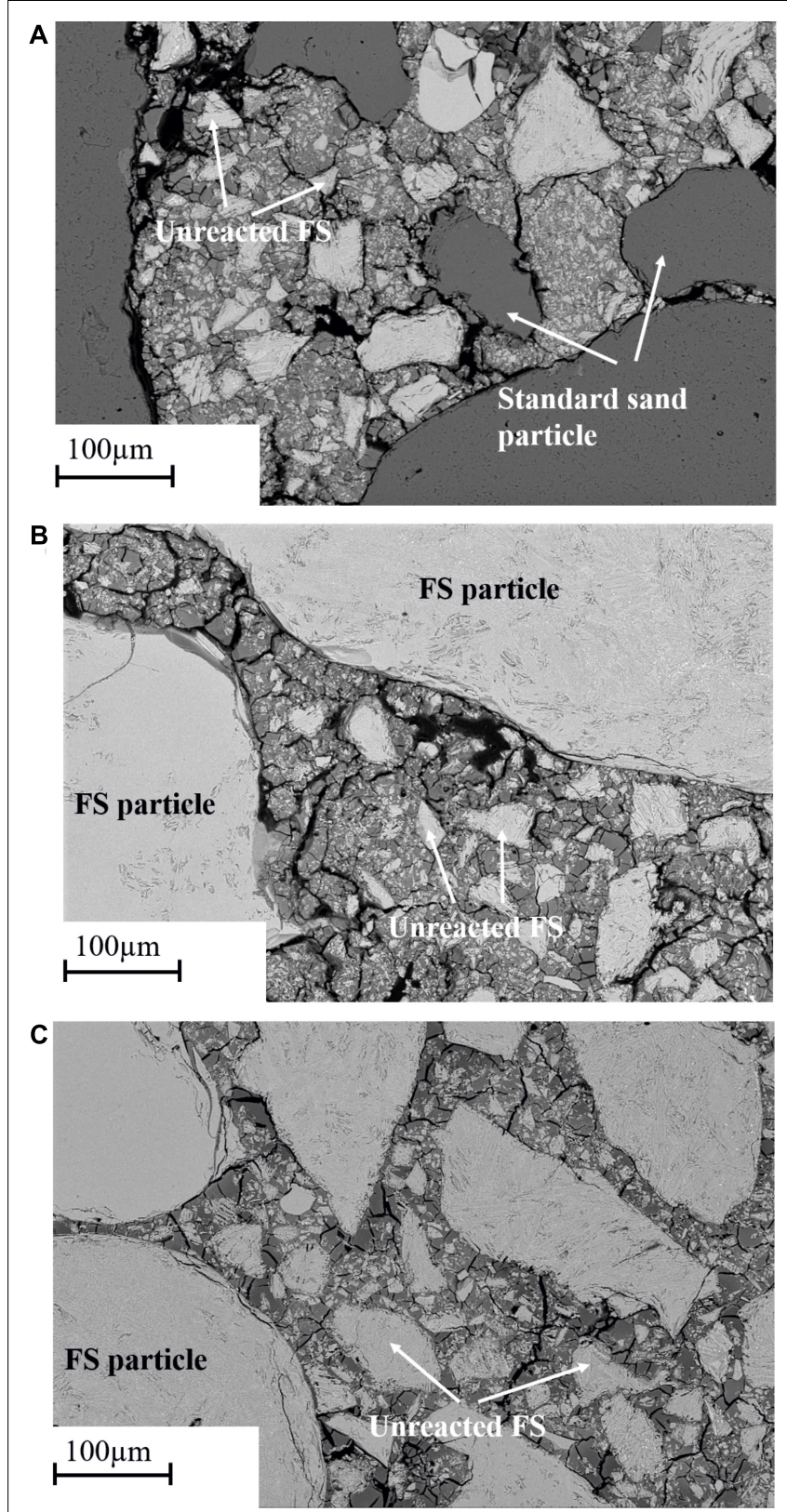

FIGURE 6 | Backscattered electron (BSE) imaging micrographs of mortar samples cured for 28 days (A) reference sample (500× magnification),

(B) AAFS1 (500× magnification), and (C) AAFS2 (500× magnification).
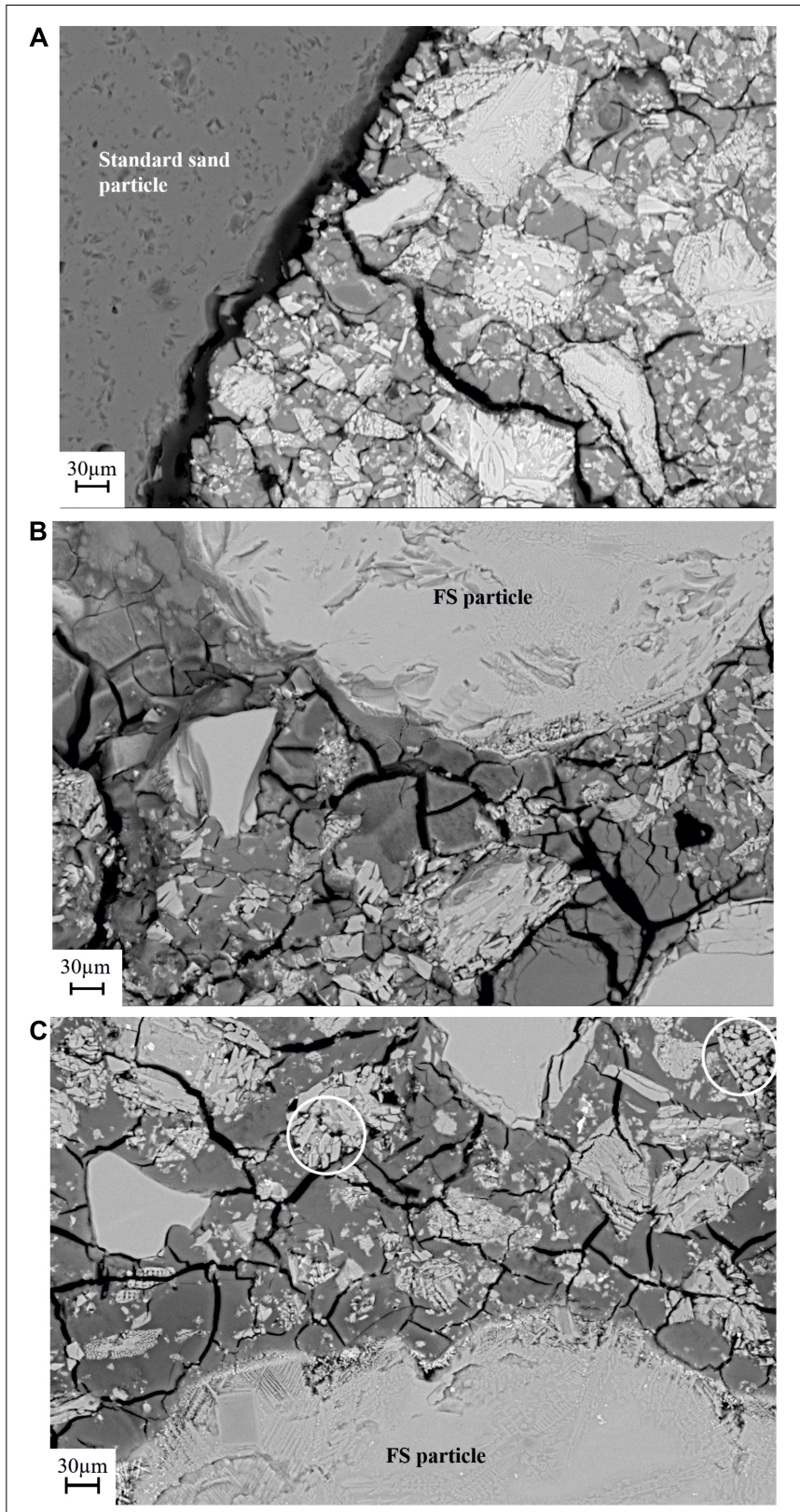

FIGURE 7 | BSE-SEM image (2000 $\times$ magnification) of the mortar samples cured at 28 days. (A) Reference sample, (B) AAFS1, and (C) AAFS2. White rings show the dissolution of the amorphous/glass phase into the binder phase. binder matrix. As compared to the glass composition of FS, the average concentration of $\mathrm{Na}$ and $\mathrm{Si}$ are higher in the binder gel formed and these elements are originating from the activating solution and those dissolved from the slag. Similar observation was reported in the binder gel of inorganic polymers made from plasma convertor slag (Kriskova et al., 2015). Additionally, the average concentration of $\mathrm{Al}$ and $\mathrm{Ca}$ are higher and $\mathrm{Mg}$ and $\mathrm{Fe}$ lower in the binder gel as compared to the glass composition.

In all the mortar samples, the average $\mathrm{Na}$ concentration are similar due to similar sodium oxide composition used for all the mixes. However, the average concentration of other elements such as $\mathrm{Fe}, \mathrm{Si}, \mathrm{Ca}, \mathrm{Al}$, and $\mathrm{Mg}$ are higher in AAFS2 and AAFS1 in comparison to the reference mortars. Fe is present in large quantities in the binder gel formed, indicating that Fe-containing phases do dissolve in alkaline environment and is consistent with the observation of other studies on alkali activation of Fe-rich slags and glasses (Machiels et al., 2014; Onisei et al., 2015; Peys et al., 2019a). The higher amount of Fe in the binder gel of AAFS2 could have influenced its properties and this is supported 


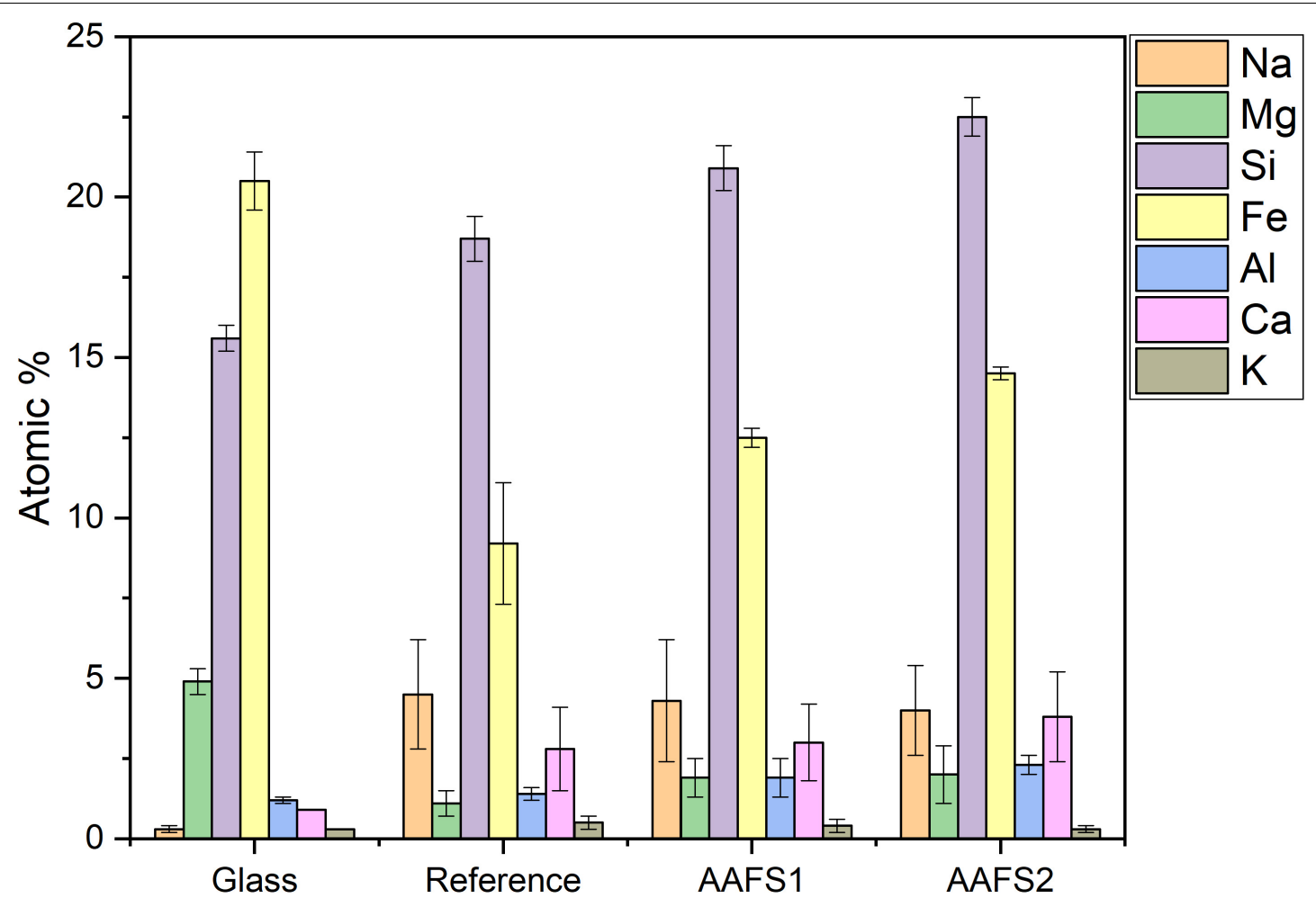

FIGURE 8 | Average atomic percentage of the binder phase of mortar samples obtained by EDS analysis. "Glass" refers to the glass composition of amorphous phase in FS. Average atomic percentage were calculated from an average of 50 data points at different locations on the binding phase and the error values present double standard deviation.

by some studies where the positive role of Fe in alkali activation synthesis of FS, volcanic ash, Fe-rich glasses, and phyllite have been reported (Lemougna et al., 2013; Onisei et al., 2018; Simon et al., 2018; Adesanya et al., 2020).

\section{CONCLUSION}

In this study, an Fe-rich water-cooled granular FS from nickel processing was investigated as a sole solid precursor in alkaliactivated mortars with and without particle size optimization. The mortar samples were evaluated in terms of workability, compressive strength, microstructural integrity, and the chemical composition of the binder. The properties of the alkali-activated mortars produced were mainly influenced by the aggregate type and particle packing. The use of FS as an aggregate and binder resulted in mortar samples with better mechanical performance compared to mortar samples with standard sand aggregates. The higher compressive strength achieved by FS aggregate mortars was due to the participation of FS aggregates in the hardening reaction, which contributed to the interfacial bonding and binder gel composition of the mortars. In contrast, the lower strength in standard sand aggregate-based mortars was due to the low chemical interaction between standard sand and the binder gel. The binder gel in all samples consisted of $\mathrm{Na}, \mathrm{Fe}$, and $\mathrm{Si}$, with lower quantities of $\mathrm{Ca}, \mathrm{Mg}, \mathrm{K}$, and $\mathrm{Al}$.
Further optimization of the PSD of the FS aggregates significantly improved the workability, microstructural integrity, and fresh and hardened properties of the mortar. The compressive strength increased from 20 to $40 \mathrm{MPa}$, and the mortar had a denser structure depicted by the higher UPV value and bulk density once the PSD was optimized. In addition, mortar with an optimized PSD had better flowability.

The mechanical performance of FS aggregate-based mortars was 20-40 MPa, depending on the particle packing optimization, demonstrating their suitability as potential construction materials for building bricks, road pavement, and tiles. Overall, the successful utilization of FS as an aggregate and binder in alkali-activated mortar provides a new, sustainable, and costeffective pathway for recycling industrial residue and can reduce the impact of solid waste on the environment.

\section{DATA AVAILABILITY STATEMENT}

The raw data supporting the conclusions of this article will be made available by the authors, without undue reservation.

\section{AUTHOR CONTRIBUTIONS}

AA: conceptualization, methodology, validation, formal analysis, investigation, visualization, writing (original draft), and writing 
(review and editing). JY: conceptualization, methodology, validation, writing (review and editing), funding acquisition, and project administration. MI: conceptualization, writing (review and editing), funding acquisition, and project administration. All authors contributed to the article and approved the submitted version.

\section{FUNDING}

This work was done as a part of the GEOBOT project supported by the European Regional Development Fund (ERDF), Pohjois-Pohjanmaa Council of Oulu Region and various companies (Boliden Harjavalta Oy, Keliber Oy, and Saint Gobain Finland Oy). AA received funding from the K. H. Renlund Foundation and Finnish Cultural Foundation toward his doctoral

\section{REFERENCES}

Adediran, A. (2017). Alkali Activation of Fayalite Slag. Master Thesis. Oulu: University of Oulu.

Adediran, A., Lemougna, P. N., Yliniemi, J., Tanskanen, P., Kinnunen, P., Roning, J., et al. (2021). Recycling glass wool as a fluxing agent in the production of clayand waste-based ceramics. J. Clean. Prod. 289:125673. doi: 10.1016/j.jclepro. 2020.125673

Adediran, A., Yliniemi, J., and Illikainen, M. (2019). Fayalite slag as binder and aggregate in alkali-activated materials-interfacial transition zone study. Proceedings 34:1. doi: 10.3390/proceedings2019034001

Adesanya, E., Ohenoja, K., Yliniemi, J., and Illikainen, M. (2020). Mechanical transformation of phyllite mineralogy toward its use as alkali-activated binder precursor. Miner. Eng. 145:106093. doi: 10.1016/j.mineng.2019.106093

Albitar, M., Mohamed Ali, M. S., Visintin, P., and Drechsler, M. (2015). Effect of granulated lead smelter slag on strength of fly ash-based geopolymer concrete. Constr. Build. Mater. 83, 128-135. doi: 10.1016/j.conbuildmat.2015.03.009

Alex, J., Dhanalakshmi, J., and Ambedkar, B. (2016). Experimental investigation on rice husk ash as cement replacement on concrete production. Constr. Build. Mater. 127, 353-362. doi: 10.1016/j.conbuildmat.2016.09.150

Ali, M. B., Saidur, R., and Hossain, M. S. (2011). A review on emission analysis in cement industries. Renew. Sustain. Energy Rev. 15, 2252-2261.

Al-Jabri, K. S., Al-Saidy, A. H., and Taha, R. (2011). Effect of copper slag as a fine aggregate on the properties of cement mortars and concrete. Constr. Build. Mater. 25, 933-938. doi: 10.1016/j.conbuildmat.2010.06.090

ASTM C34-03 (2003). Specification for Structural Clay Load-Bearing Wall Tile. West Conshohocken, PA: ASTM International.

ASTM C62 (1999). ASTM C62-99: Standard Specification for Building Brick. Solid Masonry Units Made From Clay or Shale. West Conshohocken, PA: ASTM International.

ASTM C642 (2013). Standard Test Method for Density, Absorption, and Voids in Hardened Concrete. West Conshohocken, PA: ASTM International.

Ayano, T., and Sakata, K. (2000). Durability of concrete with copper slag fine aggregate. Spec. Publ. 192, 141-158. doi: 10.14359/5746

Carvelli, V., Veljkovic, A., Nguyen, H., Adediran, A., Kinnunen, P., Ranjbar, N., et al. (2020). Low-velocity impact of hot-pressed PVA fiber-reinforced alkaliactivated stone wool composites. Cem. Concr. Compos. 114:103805. doi: 10. 1016/j.cemconcomp.2020.103805

Cristelo, N., Coelho, J., Miranda, T., Palomo, Á, and Fernández-Jiménez, A. (2019). Alkali activated composites - an innovative concept using iron and steel slag as both precursor and aggregate. Cem. Concr. Compos. 103, 11-21. doi: 10.1016/j. cemconcomp.2019.04.024

Dimitrioglou, N., Tsakiridis, P. E., Katsiotis, N. S., Katsiotis, M. S., Perdikis, P., and Beazi, M. (2015). Production and characterization of concrete paving blocks containing ferronickel slag as a substitute for aggregates. Waste Biomass Valorization 7, 941-951. doi: 10.1007/s12649-015-9465-1 research. JY received funding from the Academy of Finland (grant number 322786).

\section{ACKNOWLEDGMENTS}

Jarno Karvonen, Kaisu Ainassaari, and Tun Nyo are acknowledged for their contributions to the laboratory work. The authors wish to thank the Centre for Material Analysis, University of Oulu, Finland.

\section{SUPPLEMENTARY MATERIAL}

The Supplementary Material for this article can be found online at: https://www.frontiersin.org/articles/10.3389/fbuil. 2021.653466/full\#supplementary-material

EN 196-1 (2016). Methods of testing cement. Determination of strength. London: British Standards Institution.

EN 933-1 (2000). Tests for geometrical properties of aggregates. Determination of particle size distribution. Sieving method. London: British Standards Institution.

Fan, Y., Shibata, E., Iizuka, A., and Nakamura, T. (2014). Crystallization behaviors of copper smelter slag studied using time-temperature-transformation diagram. Mater. Trans. 55, 958-963. doi: 10.2320/matertrans.M-M2014819

Ghosh, R., Sagar, S. P., Kumar, A., Gupta, S. K., and Kumar, S. (2018). Estimation of geopolymer concrete strength from ultrasonic pulse velocity (UPV) using high power pulser. J. Build. Eng. 16, 39-44. doi: 10.1016/j.jobe.2017.12.009

Hertel, T., Blanpain, B., and Pontikes, Y. (2016). A proposal for a $100 \%$ use of bauxite residue towards inorganic polymer mortar. J. Sustain. Metall. 2, 394-404. doi: 10.1007/s40831-016-0080-6

Iacobescu, R. I., Cappuyns, V., Geens, T., Kriskova, L., Onisei, S., Jones, P. T., et al. (2017). The influence of curing conditions on the mechanical properties and leaching of inorganic polymers made of fayalitic slag. Front. Chem. Sci. Eng. 11:317-327. doi: 10.1007/s11705-017-1622-6

Kalinkin, A. M., Kumar, S., Gurevich, B. I., Alex, T. C., Kalinkina, E. V., Tyukavkina, V. V., et al. (2012). Geopolymerization behavior of $\mathrm{Cu}-\mathrm{Ni}$ slag mechanically activated in air and in CO2 atmosphere. Int. J. Miner. Process. 11, 101-106. doi: 10.1016/j.minpro.2012.05.001

Kaze, C. R., Lecomte-Nana, G. L., Kamseu, E., Camacho, P. S., Yorkshire, A. S., Provis, J. L., et al. (2021a). Mechanical and physical properties of inorganic polymer cement made of iron-rich laterite and lateritic clay: a comparative study. Cem. Concr. Res. 140:106320. doi: 10.1016/j.cemconres.2020.106320

Kaze, C. R., Tome, S., Lecomte-Nana, G. L., Adesina, A., Essaedi, H., Das, S. K., et al. (2021b). Development of alkali-activated composites from calcined iron-rich laterite soil. Materialia 15:101032. doi: 10.1016/j.mtla.2021.101032

Khanzadi, M., and Behnood, A. (2009). Mechanical properties of high-strength concrete incorporating copper slag as coarse aggregate. Constr. Build. Mater. 23, 2183-2188. doi: 10.1016/j.conbuildmat.2008.12.005

Komnitsas, K., Bartzas, G., Karmali, V., Petrakis, E., Kurylak, W., Pietek, G., et al. (2019). Assessment of alkali activation potential of a polish ferronickel slag. Sustainability 11:1863. doi: 10.3390/su11071863

Komnitsas, K., Yurramendi, L., Bartzas, G., Karmali, V., and Petrakis, E. (2020). Factors affecting co-valorization of fayalitic and ferronickel slags for the production of alkali activated materials. Sci. Total Environ. 721:137753. doi: 10.1016/j.scitotenv.2020.137753

Komnitsas, K., Zaharaki, D., and Perdikatsis, V. (2007). Geopolymerisation of low calcium ferronickel slags. J. Mater. Sci. 42, 3073-3082. doi: 10.1007/s10853-0060529-2

Kriskova, L., Machiels, L., and Pontikes, Y. (2015). Inorganic polymers from a plasma convertor slag: effect of activating solution on microstructure and properties. J. Sustain. Metall. 1, 240-251. doi: 10.1007/s40831-015-0022-8

Lemougna, P. N., Adediran, A., Yliniemi, J., Ismailov, A., Levanen, E., Tanskanen, P., et al. (2020). Thermal stability of one-part metakaolin geopolymer 
composites containing high volume of spodumene tailings and glass wool. Cem. Concr. Compos. 114:103792. doi: 10.1016/j.cemconcomp.2020.103792

Lemougna, P. N., MacKenzie, K. J. D., Jameson, G. N. L., Rahier, H., and Melo, U. F. C. (2013). The role of iron in the formation of inorganic polymers (geopolymers) from volcanic ash: a 57Fe Mössbauer spectroscopy study. J. Mater. Sci. 48, 5280-5286. doi: 10.1007/s10853-013-7319-4

Lyu, K., Garboczi, E. J., She, W., and Miao, C. (2019). The effect of rough vs. smooth aggregate surfaces on the characteristics of the interfacial transition zone. Cem. Concr. Compos. 99, 49-61. doi: 10.1016/j.cemconcomp.2019.03.001

Machiels, L., Arnout, L., Jones, P. T., Blanpain, B., and Pontikes, Y. (2014). Inorganic polymer cement from Fe-Silicate glasses: varying the activating solution to glass ratio. Waste Biomass Valorization 5, 411-428. doi: 10.1007/ s12649-014-9296-5

Machiels, L., Arnout, L., Yan, P., Jones, P. T., Blanpain, B., and Pontikes, Y. (2017). Transforming enhanced landfill mining derived gasification/vitrification glass into low-carbon inorganic polymer binders and building products. J. Sustain. Metall. 3, 405-415. doi: 10.1007/s40831-016-0105-1

Marangoni, M., Arnout, L., Machiels, L., Pandelaers, L., Bernardo, E., Colombo, P., et al. (2016). Porous, sintered glass-ceramics from inorganic polymers based on fayalite slag. J. Am. Ceram. Soc. 99, 1985-1991. doi: 10.1111/jace.14224

Mermerdaş, K., Manguri, S., Nassani, D. E., and Oleiwi, S. M. (2017). Effect of aggregate properties on the mechanical and absorption characteristics of geopolymer mortar. Eng. Sci. Technol. Int. J. 20, 1642-1652. doi: 10.1016/j. jestch.2017.11.009

Michailova, I., and Mehandjiev, D. (2010). Characterization of fayalite from copper slags. J. Univ. Chem. Technol. Metall. 45, 317-326.

Millán-Corrales, G., Magallanes-Rivera, R. X., González-López, J. R., ZaldivarCadena, A. A., and Figueroa-Torres, M. Z. (2020). Synthesis of an alternative hydraulic binder by alkali activation of a slag from lead and zinc processing. Waste Biomass Valorization 11, 375-388. doi: 10.1007/s12649-018-0363-1

Mithun, B. M., and Narasimhan, M. C. (2015). Performance of alkali activated slag concrete mixes incorporating copper slag as fine aggregate. J. Clean. Prod. 112, $837-844$.

Mo, K. H., Alengaram, U. J., Jumaat, M. Z., Yap, S. P., and Lee, S. C. (2016). Green concrete partially comprised of farming waste residues: a review. J. Clean. Prod. 117, 122-138. doi: 10.1016/j.jclepro.2016.01.022

Mo, K. H., Johnson Alengaram, U., Jumaat, M. Z., and Yap, S. P. (2015). Feasibility study of high volume slag as cement replacement for sustainable structural lightweight oil palm shell concrete. J. Clean. Prod. 91, 297-304. doi: 10.1016/ j.jclepro.2014.12.021

Nazer, A., Payá, J., Borrachero, M. V., and Monzó, J. (2016). Use of ancient copper slags in Portland cement and alkali activated cement matrices. J. Environ. Manage. 167, 115-123.

Omer, S. A., Demirboga, R., and Khushefati, W. H. (2015). Relationship between compressive strength and UPV of GGBFS based geopolymer mortars exposed to elevated temperatures. Constr. Build. Mater. 94, 189-195. doi: 10.1016/j. conbuildmat.2015.07.006

Onisei, S., Douvalis, A. P., Malfliet, A., Peys, A., and Pontikes, Y. (2018). Inorganic polymers made of fayalite slag: on the microstructure and behavior of Fe. J. Am. Ceram. Soc. 101, 2245-2257. doi: 10.1111/jace.15420

Onisei, S., Lesage, K., Blanpain, B., and Pontikes, Y. (2015). Early age microstructural transformations of an inorganic polymer made of fayalite slag. J. Am. Ceram. Soc. 98, 2269-2277.

Peys, A., Douvalis, A. P., Hallet, V., Rahier, H., Blanpain, B., and Pontikes, Y. (2019a). Inorganic polymers from $\mathrm{CaO}-\mathrm{FeOx}-\mathrm{SiO} 2$ slag: the start of oxidation of Fe and the formation of a mixed valence binder. Front. Mater. 6:212. doi: 10.3389/fmats.2019.00212

Peys, A., Douvalis, A. P., Siakati, C., Rahier, H., Blanpain, B., and Pontikes, Y. (2019b). The influence of air and temperature on the reaction mechanism and molecular structure of Fe-silicate inorganic polymers. J. Non Cryst. Solids 526:119675. doi: 10.1016/j.jnoncrysol.2019.119675

Peys, A., White, C. E., Rahier, H., Blanpain, B., and Pontikes, Y. (2019c). Alkaliactivation of $\mathrm{CaO}-\mathrm{FeOx}-\mathrm{SiO} 2$ slag: formation mechanism from in-situ X-ray total scattering. Cem. Concr. Res. 122, 179-188. doi: 10.1016/j.cemconres.2019. 04.019

Provis, J. L. (2018). Alkali-activated materials. Cem. Concr. Res. 114, 40-48. doi: 10.1016/j.cemconres.2017.02.009

Rietveld, H. M. (1969). A profile refinement method for nuclear and magnetic structures. J. Appl. Crystallogr. 2, 65-71. doi: 10.1107/S002188986900 6558

Rodrigue Kaze, C., Ninla Lemougna, P., Alomayri, T., Assaedi, H., Adesina, A., Kumar Das, S., et al. (2021). Characterization and performance evaluation of laterite based geopolymer binder cured at different temperatures. Constr. Build. Mater. 270:121443. doi: 10.1016/j.conbuildmat.2020.121443

Saari, V., Latostenmaa, P., Yliniemi, J., and Ohenoja, K. (2019). "Boliden Harjavalta copper and nickel smelter - review of smelter operations, slags and slag valorisation studies,"in Proceedings of the 6th International Slag Valorisation Symposium, Mechelen, 4.

Scrivener, K. L., John, V. M., and Gartner, E. M. (2016). Eco-Efficient Cements: Potential, Economically Viable Solutions for a Low CO2, Cement Based Materials Industry. Nairobi: United Nations Environment Programme.

SFS-EN 1015-3 (1999). Methods of Test for Mortar for Masonry. Part 3: Determination of Consistence of Fresh Mortar (by Flow Table). Stockholm: Swedish Institute for Standards.

SFS-EN 196-1 (2011). Methods of Testing Cement. Part 1: Determination of Strength. Stockholm: Swedish Institute for Standards.

Shi, C., Jiménez, A. F., and Palomo, A. (2011). New cements for the 21st century: the pursuit of an alternative to Portland cement. Cem. Concr. Res. 41, 750-763. doi: 10.1016/j.cemconres.2011.03.016

Siakati, C., Douvalis, A. P., Ziogas, P., Peys, A., and Pontikes, Y. (2020). Impact of the solidification path of $\mathrm{FeOx}-\mathrm{SiO} 2$ slags on the resultant inorganic polymers. J. Am. Ceram. Soc. 103, 2173-2184. doi: 10.1111/jace.16869

Simon, S., Gluth, G. J. G., Peys, A., Onisei, S., Banerjee, D., and Pontikes, Y. (2018). The fate of iron during the alkali-activation of synthetic (CaO-)FeOxSiO2 slags: an Fe K-edge XANES study. J. Am. Ceram. Soc. 101, 2107-2118. doi: $10.1111 /$ jace. 15354

Trtnik, G., Kavčič, F., and Turk, G. (2009). Prediction of concrete strength using ultrasonic pulse velocity and artificial neural networks. Ultrasonics 49, 53-60. doi: 10.1016/j.ultras.2008.05.001

Xia, M., Muhammad, F., Zeng, L., Li, S., Huang, X., Jiao, B., et al. (2019). Solidification/stabilization of lead-zinc smelting slag in composite based geopolymer. J. Clean. Prod. 209, 1206-1215. doi: 10.1016/j.jclepro.2018. 10.265

Zhao, H., Sun, W., Wu, X., and Gao, B. (2015). The properties of the selfcompacting concrete with fly ash and ground granulated blast furnace slag mineral admixtures. J. Clean. Prod. 95, 66-74. doi: 10.1016/j.jclepro.2015. 02.050

Conflict of Interest: The authors declare that the research was conducted in the absence of any commercial or financial relationships that could be construed as a potential conflict of interest.

Copyright ( $(2021$ Adediran, Yliniemi and Illikainen. This is an open-access article distributed under the terms of the Creative Commons Attribution License (CC BY). The use, distribution or reproduction in other forums is permitted, provided the original author(s) and the copyright owner(s) are credited and that the original publication in this journal is cited, in accordance with accepted academic practice. No use, distribution or reproduction is permitted which does not comply with these terms. 